Review Article

\title{
Antioxidants from Plants Protect against Skin Photoaging
}

\author{
Ganna Petruk, ${ }^{1}$ Rita Del Giudice, ${ }^{2}$ Maria Manuela Rigano $\left(\mathbb{D},{ }^{3}\right.$ and Daria Maria Monti $\mathbb{D}{ }^{1,4}$ \\ ${ }^{1}$ Department of Chemical Sciences, University of Naples Federico II, Complesso Universitario Monte Sant'Angelo, via Cinthia 4, \\ 80126 Naples, Italy \\ ${ }^{2}$ Department of Experimental Medical Science, Lund University, 22184 Lund, Sweden \\ ${ }^{3}$ Department of Agricultural Sciences, University of Naples Federico II, via Università 100, 80055 Portici, Naples, Italy \\ ${ }^{4}$ Istituto Nazionale di Biostrutture e Biosistemi (INBB), Rome, Italy
}

Correspondence should be addressed to Daria Maria Monti; mdmonti@unina.it

Received 26 April 2018; Revised 5 July 2018; Accepted 11 July 2018; Published 2 August 2018

Academic Editor: Laura Bravo

Copyright ( 2018 Ganna Petruk et al. This is an open access article distributed under the Creative Commons Attribution License, which permits unrestricted use, distribution, and reproduction in any medium, provided the original work is properly cited.

\begin{abstract}
Exposure to UV light triggers the rapid generation and accumulation of reactive oxygen species (ROS) in skin cells, with consequent increase in oxidative stress and thus in photoaging. Exogenous supplementation with dietary antioxidants and/or skin pretreatment with antioxidant-based lotions before sun exposure might be a winning strategy against age-related skin pathologies. In this context, plants produce many secondary metabolites to protect themselves from UV radiations and these compounds can also protect the skin from photoaging. Phenolic compounds, ascorbic acid and carotenoids, derived from different plant species, are able to protect the skin by preventing UV penetration, reducing inflammation and oxidative stress, and influencing several survival signalling pathways. In this review, we focus our attention on the double role of oxidants in cell metabolism and on environmental and xenobiotic agents involved in skin photoaging. Moreover, we discuss the protective role of dietary antioxidants from fruits and vegetables and report their antiaging properties related to the reduction of oxidative stress pathways.
\end{abstract}

\section{Introduction}

Reactive oxygen species (ROS) are normally produced in cell metabolism, but, when the balance between free radicals and antioxidants favours the former, they can also take part in a pathological process known as oxidative stress. Oxidative stress may result in cell damage, thus leading to the development of many types of diseases, as well as aging [1]. With aging, a decreased performance of cell endogenous antioxidant system occurs; thus, elderly people are more susceptible to oxidative stress $[2,3]$. Several secondary plant metabolites are endowed with antioxidant activity and have been studied to prevent, retard, and control the development of age-related pathologies [4]. The skin is considered the largest organ with a protective role against external noxious sources, such as UV radiations. In particular, exposure to UV light triggers the rapid generation and accumulation of ROS in skin cells, which may result in photoaging. In this review, we focus our attention on the role of oxidants in their physiological context and in pathological conditions, with a special attention on skin photoaging. Then, the protective role of antioxidants from fruits and vegetables is discussed. Their antiaging properties, related to the activity of intracellular oxidative stress pathways, are reported.

\section{Physiological Role of Oxidants}

All life processes are governed by redox signalling; thus, the maintenance of a physiological level of oxidants is mandatory for proper cellular functioning. This can be obtained by switching on/off some regulation pathways or programmed cell death. Oxidants are responsible for a well-known process, senescence, as they are involved in telomere shortening. Different authors demonstrated that cells grown in the presence of strong oxidative environments have a shorter life span compared with cells grown in low oxygen tension [5-7]. Indeed, oxygen is one of the most abundant oxidants. This chemical element is necessary for all aerobic organisms and acts as terminal oxidant in the mitochondrial respiratory 
chain, which is the main source of energy for the cell [8]. In eukaryotic cells, oxygen can be partially reduced by several enzymatic and nonenzymatic reactions, thus inducing the production of reactive intermediates, such as superoxide radical $\left(\mathrm{O}_{2}^{\bullet-}\right)$, peroxyl $\left(\mathrm{ROO}^{\bullet}\right)$, alkoxyl $\left(\mathrm{RO}^{\bullet}\right)$, and hydroxyl $\left(\mathrm{HO}^{\circ}\right)$, better known as reactive oxygen species (ROS). All these molecules need to be stabilized by reacting with other molecules, such as nitric oxide $\left(\mathrm{NO}^{\bullet}\right)$, and forming reactive nitrogen species (RNS). This constitutes the basis for the formation of a multitude of additional oxidative signalling elements, including the highly reactive and potentially damaging peroxynitrite $\left(\mathrm{ONOO}^{-}\right)[9,10]$. Both ROS and RNS may target cysteine thiols, leading to oxidative modifications and to the formation of reactive sulphur species (RSS) [11].

Despite this, a small, nontoxic increase in ROS levels plays a key role in the prevention of the insurgence of different diseases by assisting the immune system, mediating cell signalling, and playing an essential role in apoptosis [12]. Indeed, ROS can alter the mitochondrial membrane potential and induce the release of cytochrome $c$, which induces caspase activation [13]. Cellular oxidants are mainly by-products of endogenous processes: (1) mitochondrial ATP production, (2) phagocytosis, (3) $\beta$-oxidation of long-chain fatty acids (>C20), and (4) other metabolic pathways, such as inflammation $[14,15]$. Normally, damages caused by free radicals are repaired by a class of molecules named antioxidants. However, when antioxidant defences are not adequate, that is, when excessive amounts of free radicals are generated, the cell undergoes oxidative stress. In this condition, several damages may occur at protein, enzyme, lipid, and nucleic acid levels. In the latter, the production of reactive singlet oxygen can react with all DNA bases. More in detail, when the single oxygen reacts with guanine, the process generates 8 -oxo-7,8-dihydro- 2 '-deoxyguanosine (8-oxo-dG) [16]. While guanine normally pairs with cytosine, 8-oxo-dG pairs with adenine; thus, the resulting point mutation will be translated in a mutated protein.

Generally, cell damages may alter downstream cell signalling and cause a variety of diseases, such as cardiovascular diseases, neurodegenerative disorders, cancers, and also aging, including skin aging [17-25].

\section{Environmental and Xenobiotic Agents Involved in Skin Aging}

Aging is a complex biological process, as it induces progressive deterioration of anatomical structures and of the physiological functions of the organs [26]. The skin is the outermost barrier of the body and the biggest organ, and its changes are among the most visible signs of aging. Indeed, with aging, the skin loses some of its properties, such as elasticity, thickness, and colour [27]. The normal cellular oxidative metabolism can generate different by-products responsible for molecular damage, thus contributing to skin aging (intrinsic aging). However, it has been reported that up to $80-90 \%$ of skin aging is due to environmental and xenobiotic agents (extrinsic aging) [26, 28].

Several external factors may represent a cause of free radical production and consequently induce skin aging. Among them, it is worth mentioning air and water contaminants, tobacco smoke, different organic solvents, several drugs (such as bleomycin and gentamycin), kitchen scraps (i.e., used oil and fat), and heavy or transition metals (such as lead, cadmium, mercury, and iron) ([18] and references therein). In particular, air pollution includes biological and gaseous contaminants, as well as particulate. Pollution has been reported to exert deleterious effects on the skin in different ways [29]: (a) ultrafine particles can penetrate tissues and localize in mitochondria, thus inducing ROS generation [30]; (b) diesel exhaust particles induce activation of the inflammatory cascade in keratinocytes [31]; (c) pollutants are among the activators of the aryl hydrocarbon receptor (AhR), a cytosolic ligand-activated transcription factor that regulates cellular proliferation, inflammation, and melanogenesis [32]; and (d) pollutants can alter skin microflora $[33,34]$. Another external stress factor is arsenic. This chemical element is widely present in food, water, air, and soil and is mostly found in its trivalent $\left(\mathrm{As}^{3+}\right.$, such as sodium arsenite and arsenic trioxide) or pentavalent $\left(\mathrm{As}^{5+}\right)$ inorganic form. There are many pieces of evidence demonstrating that the deleterious effects of trioxide arsenic are mostly due to its inorganic state, rather than to the organic form [35-37], since it induces the generation of free radicals in cells and, consequently, leads to oxidative stress, resulting in oxidative DNA damage and finally into apoptosis [38-42].

Tobacco smoking has been underestimated as stress factor for a long time and its damages have resulted more evident with the increase of life expectancy [43, 44]. Smoking dates back to as early as $5000 \mathrm{BC}$ in the Americas in shamanistic rituals [45], but the first report that described a link between smoking and cancer was published in 1928 [46]. To date, in PubMed, there are more than 53,000 research entries on this theme. Despite that, millions of people continue to smoke and the risk of cancer, as well as premature skin aging, is ignored $[47,48]$.

Nowadays, sunlight is among the most harmful exogenous factors able to induce ROS formation. The spectrum of sunlight includes infrared energy (above $760 \mathrm{~nm}$ ), visible light (400-760 nm), and ultraviolet (UV) light (below $400 \mathrm{~nm}$ ) [49]. UV radiations can be further divided in UVA (400$315 \mathrm{~nm})$, UVB (315-280 nm), and UVC (280-100 nm). Photobiological responses are mostly generated by exposure to UVB and UVA radiations. UV radiations are the major cause of stem cell DNA damage; they can contribute to depletion of stem cells and damage of stem cell niche, eventually leading to photoinduced skin aging [50]. In particular, in the UVB range, direct light absorption by DNA mainly results in dimerization reactions between adjacent pyrimidine bases. Nevertheless, UVA radiations are considered more dangerous than UVB as, although they are weakly absorbed by DNA, they can excite endogenous chromophores, leading to DNA damage. Moreover, several endogenous and exogenous molecules, once exposed to photoexcitation, can lead to ROS formation [51].

\section{Skin Photoaging as a Consequence of Oxidative Stress}

Exposure to UV irradiation induces photochronical generation of ROS that activates cell surface growth factors, 
TABLE 1: Defence levels and mechanism of action of antioxidants.

\begin{tabular}{|c|c|c|c|c|c|}
\hline \multicolumn{2}{|c|}{ The first line of defence } & \multicolumn{2}{|c|}{ The second line of defence } & \multicolumn{2}{|c|}{ The third line of defence } \\
\hline Antioxidant & Mechanism of action & Antioxidant & Mechanism of action & De novo enzymes & $\begin{array}{c}\text { Mechanism } \\
\text { of action }\end{array}$ \\
\hline Superoxide dismutase & $\mathrm{O}_{2}^{\bullet-} \rightarrow \mathrm{H}_{2} \mathrm{O}_{2}$ & Ascorbic acid & \multirow{4}{*}{$\begin{array}{l}\text { Chain breaking: donate an } \\
\text { electron to the free radical }\end{array}$} & Polymerases & \multirow{4}{*}{ DNA repair } \\
\hline Catalase & $2 \mathrm{H}_{2} \mathrm{O}_{2} \rightarrow \mathrm{O}_{2}+\mathrm{H}_{2} \mathrm{O}$ & Uric acid & & Glycosylases & \\
\hline Glutathione peroxidase & $\mathrm{H}_{2} \mathrm{O}_{2}+\mathrm{GSH} \rightarrow \mathrm{GSSG}+\mathrm{H}_{2} \mathrm{O}$ & Glutathione & & Nucleases & \\
\hline Transferrin & & a-Tocopherol & & & \\
\hline \multirow{3}{*}{ Caeruloplasmin } & Metal chelators or sequesters & Ubiquinol & \multirow{3}{*}{ Incorporation of free radical } & Proteinases & \multirow{3}{*}{$\begin{array}{c}\text { Protein } \\
\text { proteolysis }\end{array}$} \\
\hline & & $\beta$-Carotene & & Proteases & \\
\hline & & Lycopene & & Peptidases & \\
\hline
\end{tabular}

cytokine receptors, and nicotinamide adenine dinucleotide phosphate (NADPH) oxidase [52]. This induces signal propagation within the cell through phosphorylation of tyrosine residues on the receptors and their associated adaptor proteins [53]. In particular, two nuclear transcription factors, activator protein 1 (AP-1) and nuclear factor- $\kappa \mathrm{B}(\mathrm{NF}-\kappa \mathrm{B})$, involved in transcription of genes for matrix-degrading enzymes and proinflammatory cytokines, respectively, are activated [54]. These transcription factors are associated with skin dryness, pigmentation, laxity, deep wrinkling $[55,56]$, and apoptosis activation $[57,58]$.

However, photoaging is a cumulative process, as many factors contribute to it, such as the degree of sun exposure and skin pigment. Indeed, it has been demonstrated that people with lighter skin colour, living in sunny countries, developed more easily skin cancers, such as basal cell cancer, squamous cell carcinoma, and melanoma [54].

To hide the effects of aging, several people undergo plastic surgery. However, in most cases, this practice is expensive, very invasive, and could potentially lead to complications. In this context, development of new antiaging therapies is gaining more importance.

During the last decade, different studies demonstrated that chronological aging and photoaging activate the same oxidative stress-related pathways. However, photoaging accounts for about $80 \%$ of the aging-related adverse effects. In this context, antioxidants are known to inhibit damages induced by oxidation, caused by ROS, as described in this review in paragraph $5[54,59,60]$.

\section{Antioxidants as Antagonists of ROS in Skin Disorders}

The aerobic world is characterized by high levels of toxic oxygen by-products. To survive in this adverse environment, the organism has evolved antioxidant systems to protect itself. Khlebnikov et al. defined the antioxidants as "any substance that directly scavenges ROS or indirectly acts to upregulate antioxidant defences or inhibit ROS production" [61]. However, antioxidants are also characterized by the ability to form a new, more stable radical, through intramolecular hydrogen bonding and further oxidation [62]. In addition, antioxidants can regulate gene expression inducing the translocation of the nuclear factor-erythroid 2-related factor 2 (Nrf-2) from the cytosol to the nucleus, upon dissociation from its inhibitor, Kelch-like erythroid cellderived protein 1 (Keap-1). Once in the nucleus, Nrf-2, can bind antioxidant response elements (ARE) and induces the transcription of stress response genes, such as glutathione S-transferase (GST), heme oxygenase-1 (HO-1), and $\mathrm{NAD}(\mathrm{P}) \mathrm{H}$ : quinone acceptor oxidoreductase 1 (NQO1) $[14,63,64]$. The defence system of the cell from oxidative stress consists of an interacting network of different antioxidants that acts at different levels and with different mechanisms, which are summarized in Table 1.

Antioxidants belonging to the first line of defence suppress the formation of free radicals, whereas those of the second line counteract the chain initiation and/or break the chain propagation reactions of free radicals. Following oxidative stress, the cell is able to induce the transcription and translation of de novo enzymes, involved in repair processes. If the cell is able to counteract the negative effects of stress injury, it will undergo adaptation and restore the physiological antioxidant levels. On the other hand, in case of prolonged or excessive stress, the cell will undergo programmed cell death, as schematically represented in Figure 1.

In general, antioxidants can be grouped as endogenous, that is, produced by the body, and exogenous, that is, obtained from the diet. The first class can be divided in enzymatic and nonenzymatic defences. The first group includes superoxide dismutase (SOD) [65], catalase [65], and glutathione peroxidase [65], whereas the nonenzymatic defenders include iron- and copper-binding extracellular proteins (e.g., albumin, transferrin, lactoferrin, haptoglobin, and ceruloplasmin) [66] as well as other cellular compounds (e.g., quinones, glutathione, uric acid, and bilirubin) [66].

Enzymatic and nonenzymatic defenders are complementary to each other, since they act against different oxidative species in different cellular compartments. Moreover, they may act in a synergistic way with the exogenous antioxidant systems. This last family of antioxidants can be divided into synthetic and natural antioxidants. Some examples for each class are reported in Table 2, with a focus on antioxidants able to protect the skin from photoaging.

\section{Fruits and Vegetables as Powerful Sources of Antiaging Antioxidants}

Exogenous supplementation with dietary antioxidants and/ or skin pretreatment with antioxidant-based lotions before 


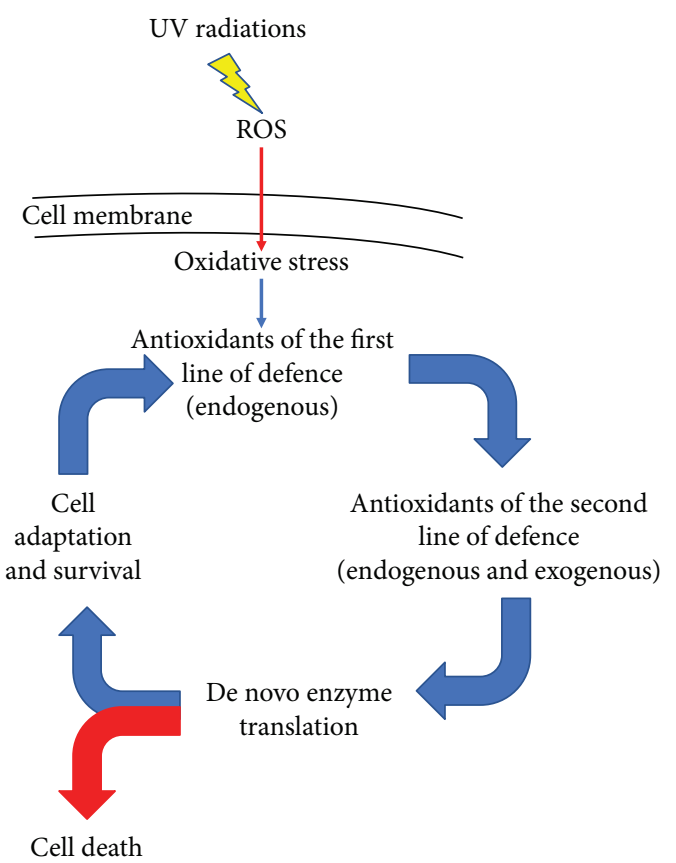

FIGURE 1: Schematic representation of the cell antioxidant response following oxidative stress injury. Upon UV radiations, ROS levels increase and oxidative stress is induced. Endogenous antioxidants suppress ROS formation and exogenous and endogenous antioxidants cooperate to suppress propagation reactions. Cell damages are repaired by de novo enzymes. Finally, if the cooperation among these antioxidant-related networks is able to counteract oxidative stress injury, the cell will survive after an adaptation process; otherwise, in case of prolonged or excessive stress, the cell will undergo cell death.

sun exposure might be a winning strategy against age-related skin oxidative damage [86]. Indeed, a regular intake of vitamins, polyunsaturated fatty acids, and polyphenols from plant sources has been shown to contribute to the prevention of age-related diseases. The search for effective natural compounds able to protect against the deleterious effects of photoaging has been intensified in recent years. Indeed, the list of molecules with antiaging potential extracted from different parts of a number of plant species is continuously growing $[87,88]$.

In this context, plants produce many secondary metabolites to protect themselves from UV radiations and these molecules can be used as natural antioxidants able to protect the skin from photoaging. These active compounds can protect the skin by (i) absorbing UV radiations, (ii) inhibiting free radical reactions induced by UV in cells, and (iii) modulating endogenous antioxidant and inflammatory systems [4, 89].

In the following part of the review, we will describe some of these natural antioxidants, the plants from which these compounds are normally extracted and their role in photoaging.

6.1. Phenolic Compounds. Natural compounds used against photoaging comprise phenolic compounds, including flavonoids (catechins, isoflavones, proanthocyanidins, and anthocyanins), phenolic acids (benzoic, gallic, and cinnamic acids), and stilbenes derived from plants such as tea, grape, bergamot, fernblock, rooibos, grapefruit, and red orange $[4,88,90]$. All these compounds can prevent penetration of radiations into the skin and, in addition, they can reduce inflammation, oxidative stress, and influence several signalling pathways in order to protect the skin against UV damage [4]. We recently demonstrated that two phenolic compounds, malvidin and cyanidin, extracted from fruits of the açai tree (Euterpe oleracea Mart.), a South American palm, were able to counteract UVA-induced oxidative stress in immortalized fibroblasts [74]. Indeed, the preincubation of UVA-irradiated BALB/3T3 cells with açai phenolic compounds interfered with ROS production and kept GSH levels and lipid peroxidation comparable to normal cellular levels [74]. In another paper, we showed the beneficial effects of water extracts from Opuntia ficus-indica L. cladodes on human keratinocytes [91]. In particular, the phenolic compounds eucomic and piscidic acids were found to be the main active molecules responsible for the protection of keratinocytes against the UVA-induced oxidative stress and apoptosis [91].

Several studies have demonstrated the health-promoting effect of grape (Vitis vinifera) against age-related diseases. This is due to the high content of phenolic compounds present in this plant. Indeed, grape seeds and peels constitute a rich source of polyphenols including quercetin, catechin, epicatechin, gallic acid, and oligomeric proanthocyanidins [4, 92]. Recently, it has been found that also grape extracts from the stems, a part of the grape tree rich in phenolic compounds, are able to reduce UVB-induced oxidative damage [93]. Indeed, the topical application of stem's grape extracts on mice skin before UVB treatment was able to prevent epidermal thickness, erythema, pigmentation, mast cell and inflammatory neutrophil infiltrations, collagen degradation, and the expression of COX-2, Nrf-2, and HO-1 genes [93].

Grape seeds are also rich in phytoalexin resveratrol (trans-3, 4',5-trihydroxy-stilbene), a polyphenolic antioxidant with strong anti-inflammatory and antiproliferative activity $[4,87]$. A single application of resveratrol on hairless mice's skin before exposure to UVB radiation led to the inhibition of skin edema, cyclooxygenase, and ornithine decarboxylase induction and lipid peroxidation in the skin $[4,76]$. Interestingly, the human skin has been shown to have specific binding sites for resveratrol. As recently reviewed by Davinelli and colleagues [94], the interaction of resveratrol with the specific binding partner is able to block apoptotic events and mitochondrial dysfunctions in keratinocytes, delaying skin aging. In human keratinocytes, resveratrol can also modulate cytokine (IL-6, IL-8, and TNF- $\alpha$ ) levels and stimulate the expression of HSP70, a factor important for cell repair and also for cytoprotection ([75] and references therein). However, one should keep in mind that resveratrol has very low solubility and high sensitivity to oxidation, thus making this molecule very unstable ([94] and references therein).

Human intervention studies have also been carried out, and most of them have focused on the supplementation of epigallocatechin gallate (EGCG) from green tea. In one of 
TABLE 2: Antioxidants involved in protection from photoaging.

\begin{tabular}{|c|c|c|c|c|}
\hline Antioxidants & Class & $\begin{array}{l}\text { Bioactive } \\
\text { compound }\end{array}$ & Skin protection from photoaging & Ref \\
\hline \multirow[t]{2}{*}{ Synthetic } & $\begin{array}{l}\text { Nitroxides } \\
\text { (mimetics of SOD) }\end{array}$ & Tempol & $\begin{array}{l}\text { Protection from UVA- and UVB-induced damage in vitro and in vivo } \\
\text { Inhibition of extracellular matrix degradation and preservation of } \\
\text { collagen production in vitro }\end{array}$ & {$[67-70]$} \\
\hline & $\begin{array}{c}\text { Coenzyme } \\
\text { Q analogues }\end{array}$ & Idebenone & $\begin{array}{l}\text { Protection from oxidative stress damage in living skin } \\
\text { Suppression of sunburn cell formation }\end{array}$ & {$[71]$} \\
\hline \multirow{6}{*}{ Natural } & \multirow[b]{2}{*}{ Flavonoids } & Quercetin & $\begin{array}{l}\text { Inhibition of UV-induced inflammation in primary human keratinocytes } \\
\text { Protection of mice skin from UV radiation-induced damage }\end{array}$ & {$[72,73]$} \\
\hline & & $\begin{array}{l}\text { Malvidin and } \\
\text { Cyanidin } \\
\text { derivatives }\end{array}$ & Protection of murine fibroblast from UVA damages & {$[74]$} \\
\hline & Polyphenols & Resveratrol & $\begin{array}{c}\text { Protection of HaCaT cells from UVB irradiation through attenuation } \\
\text { of the caspase pathway } \\
\text { Counteraction of UVB damages in hairless mice } \\
\text { Reduction of skin wrinkling and skin oxidative stress }\end{array}$ & {$[75-77]$} \\
\hline & Carotenoids & $\begin{array}{l}\beta \text {-Carotene } \\
\text { Lycopene } \\
\text { Luthein }\end{array}$ & $\begin{array}{l}\text { Prevention and repair from photoaging } \\
\text { Protection of human skin against UV radiation in human clinical studies }\end{array}$ & {$[78-80]$} \\
\hline & \multirow[t]{2}{*}{ Vitamins } & Vitamin C & $\begin{array}{c}\text { Protection of HaCaT cells from UVA irradiation through attenuation } \\
\text { of inflammation and activation of apoptosis } \\
\text { Antioxidant, photoprotection, antiaging, antipigmentary effects } \\
\text { on the skin }\end{array}$ & {$[81-84]$} \\
\hline & & Vitamin E & Skin photoprotection against UV-induced oxidative stress & {$[84,85]$} \\
\hline
\end{tabular}

these studies, human subjects received $800 \mathrm{mg}$ of EGCG, in one dose or divided in two doses, and this treatment consistently reduced the erythema size caused by the exposure to UV radiation [95]. Attention should be paid to the local EGCG concentration as, when tested in $\mathrm{nM}$ concentrations, it acts as antioxidant, whereas when tested in the $\mu \mathrm{M}$ concentration range, EGCG acts as a prooxidant [96]. In another study on human subjects, high dose of flavanols from cocoa powder alleviated the erythema size upon UV radiation exposure [97].

6.2. Vitamin C. Vitamin C (ascorbic acid) is an essential cofactor in several enzymatic reactions but, since it cannot be synthesized by the human body, it has to be introduced in the organism by diet [98]. The antioxidant activity of ascorbic acid, which is found in fruits such as acerola, orange, lemon, tangerine, and tomato, makes it a good candidate as a protective compound against UV irradiation [99, 100]. Tomato (Solanum lycopersicum) fruits are a good source of ascorbic acid. Notably, we recently demonstrated the ability of an ascorbic acid-enriched tomato genotype to fight the oxidative stress induced by UVA in normal human keratinocytes [83]. In particular, pretreatment of cells with ascorbic acid or with tomato extracts before UVA exposure was able to maintain ROS, GSH, and lipid peroxidation levels at the basal levels and there was no evidence of apoptosis or inflammation [83]. These findings have been corroborated by Pullar et al., who demonstrated that ascorbic acid prevents lipid peroxidation and protects keratinocyte exposed to UV radiation from apoptosis [100]. In humans, it has been found that ascorbic acid acts as a photoprotectant at doses above the minimal erythema dose and that stimulates collagen synthesis, protects against damage from UVA/B radiation, and mitigates inflammation in the skin $[86,99,100]$. Finally, it has been demonstrated that topical application of an antioxidant mixture containing grape seed extract, vitamin E, ubiquinone, and ascorbic acid was able to protect the human skin against infrared A radiation-induced MMP-1 upregulation [101]. Unfortunately, many factors influence vitamin C stability, such as its concentration, temperature, and the $\mathrm{pH}$ used for aqueous formulations (which should be used at a $\mathrm{pH}$ lower than its pKa) [102].

6.3. Carotenoids. Carotenoids are dietary antioxidants that have demonstrated photoprotective activity. In plants, these compounds are components of the photosynthetic machinery where they act as accessory light-harvesting pigments and protect from photooxidative damage [103]. The photoprotective effects of several carotenoids have been investigated by intervention studies in humans, in which a carotenoid-rich diet has been investigated for its ability to decrease the erythema size upon UV radiation exposure [104-106], even though a long period (at least ten weeks) is necessary for successful intervention [106].

Among carotenoids, $\beta$-carotene, lycopene, canthaxanthin, and lutein that are derived from different plant sources such as tomato, carrots, and algae are the most abundant [107]. Carotenoids capsanthin and capsorubin from red pepper (Capsicum annuum L.) fruits have also been found to have protective properties against UVB-induced DNA damage in human dermal fibroblasts [88, 108]. Indeed, cell 


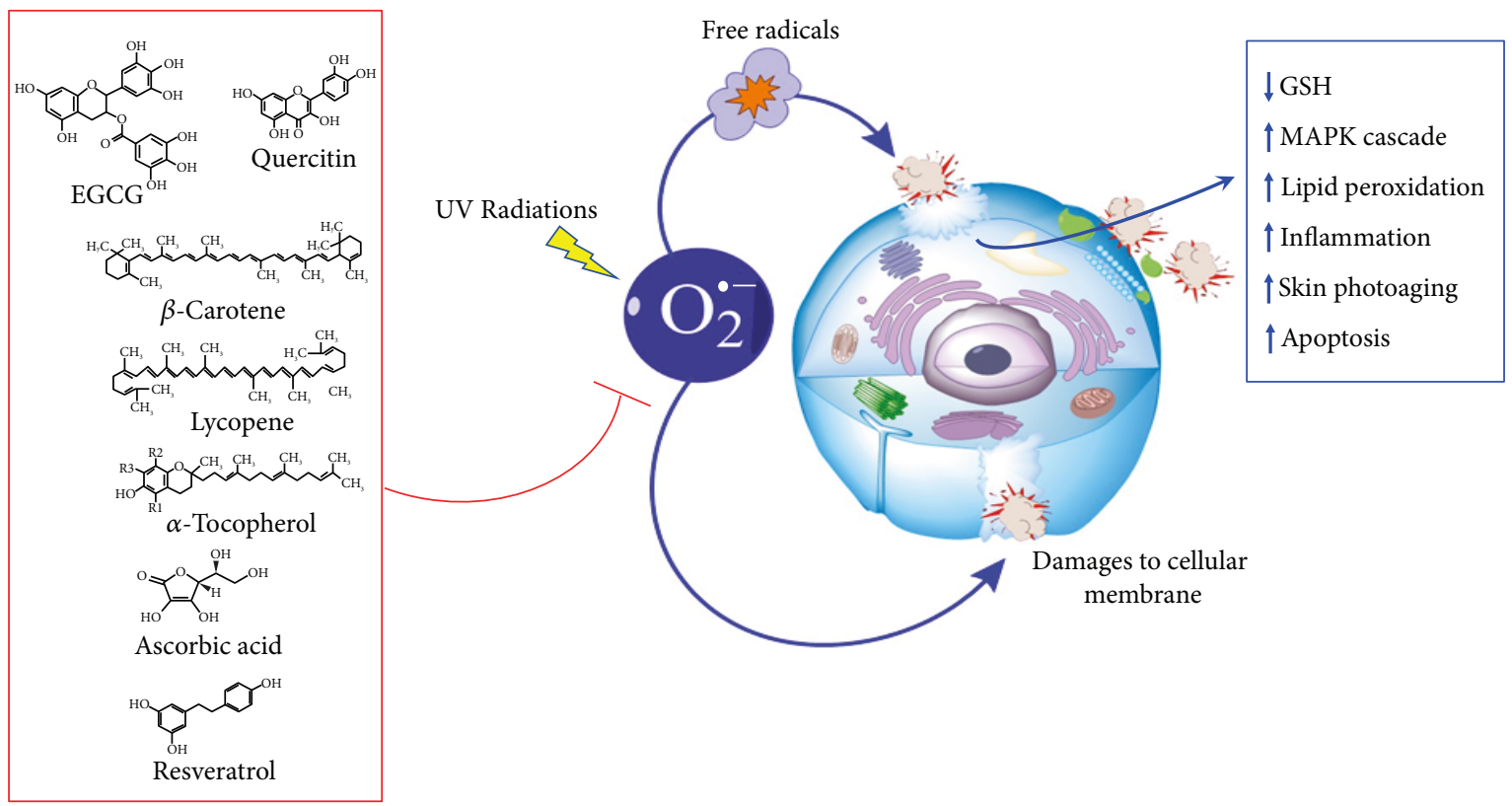

FIGURE 2: Cartoon representing cellular responses to oxidative stress in the presence (red lines) or in the absence (blue lines) of antioxidants. After oxidative stress induction by UV radiations, there is an increase in free radicals, which, in turn, induces different responses in the cell, such as depletion in GSH, activation of MAPK cascade, increase in lipid peroxidation, inflammation, skin photoaging, and apoptosis. All these processes can be inhibited or counteracted by antioxidant's activity (reported in the red box).

pretreatment with these carotenoids decreased the formation of UVB-induced DNA strand breaks and counteracted caspase- 3 activation [108]. Studies on $\beta$-carotene protective effects go back to early ' 70 s as this molecule showed very promising results. In 1996, a trial was reported on 12 years of supplementation with $\beta$-carotene $(50 \mathrm{mg}$ on alternate days) on healthy men but did not show any protective effect from melanoma insurgence [109].

Moreover, safety concerns have been recently raised with regard to its supplementation for over long periods of time [79]. Although the photoprotective effects of beta-carotene are thought to originate from its antioxidant properties, some studies documented prooxidant effects of $\beta$-carotene. For this reason, recent studies are focused on carotenoids other than $\beta$-carotene, such as lycopene, the primary carotenoid in tomatoes. We recently demonstrated that tomato extracts, rich in lycopene, are effective in counteracting the detrimental effects induced by oxidative stress caused by treatments with sodium arsenite on different human cell lines [80]. In particular, we found that carotenoids extracted from both fresh and processed tomato fruits showed cytoprotective activity, were able to mitigate ROS production induced by oxidative stress, and prevented GSH depletion and lipid peroxidation [80].

It has been demonstrated that lycopene protects against various skin alterations induced by UV radiation [90]. As an example, lycopene has been shown to have a role in the prevention of skin cancer. Indeed, lycopene preexposure on UVB-irradiated human keratinocytes was found to play a diversified role in UVB-irradiated keratinocytes, depending on the level of damage, correcting the injury in mild photodamaged cells and acting as a cytotoxic agent in preneoplastic cells [110]. In particular, in irradiated keratinocytes, lycopene pretreatment resulted in the overexpression of BAX gene, a cell cycle delay at S-phase transition, and in a consequent decrease of cells in G0/G1 phase [110].

In a placebo-controlled, double-blinded, randomized study, oral supplementation with lycopene-rich tomato nutrient complex (TNC) and lutein has been shown to be able to protect the human skin against UVA and UVA/ UVB radiations [79]. In particular, oral supplementation with TNC inhibited UV-induced upregulation of the genes heme oxygenase-1, intercellular adhesion molecule 1, and matrix metallopeptidase 1, indicators of oxidative stress, photodermatoses and photoaging [79].

Several studies suggested that the protection from UV radiation is more effective upon treatment with combined tomato antioxidant compounds, compared to the effects of lycopene treatment alone, and this is probably due to a synergistic effect of the different tomato phytonutrients $[79,111]$. This could be related to the fact that the interaction between structurally different molecules, endowed with different antioxidant properties, may provide a more comprehensive protection against oxidative injury [84].

Accordingly, consumption of tomato paste has been shown, in a randomized controlled study, to protect against acute and long-term photodamage [112]. In particular, supplementation of tomato paste before UV exposure was able to dampen skin erythema and to reduce mitochondrial DNA damage [112, 113]. Moreover, it has been recently showed that, in hairless and immunocompetent mice, tomato consumption was able to protect against the development of UVB-induced keratinocyte carcinoma [113]. 


\section{Conclusions}

Skin photoaging is a consequence of the oxidative stress generated upon exposure to UV radiation. However, the skin is normally protected from the negative effects of oxidative stress by endogenous antioxidant systems, which, unfortunately, undergo a progressive decline during aging. Several lines of evidence support the hypothesis that secondary metabolites from plants act as natural antioxidants able to decrease or retard the development and progression of life style-related diseases.

The intake of dietary antioxidants plays a fundamental role in the protection against oxidative injury; therefore, a correct diet is crucial to extend lifespan. Accordingly, several in vitro, in vivo, and human intervention studies demonstrated that antioxidants deriving from natural products, most of them assumed with the Mediterranean diet, are particularly effective in the protection of skin from photoaging, as schematically reported in Figure 2.

However, the use of natural antioxidants not only is restricted to oral diet but also includes a potential topical use against UV radiations. This is possible as some natural compounds show UV absorption properties and act as antioxidants, thus reducing the damaging effects of UV radiation exposure. Thus, increasing the antioxidant capacity of skin cells by using exogenous antioxidants could be a valuable strategy for preventing UV-induced skin damage.

\section{Conflicts of Interest}

The authors declared no potential conflicts of interest with respect to the research, authorship, and/or publication of this article.

\section{Authors' Contributions}

All authors contributed to write the review article and have read and approved the final manuscript.

\section{References}

[1] C. Nishigori, Y. Hattori, Y. Arima, and Y. Miyachi, "Photoaging and oxidative stress," Experimental Dermatology, vol. 12, Supplement 2, pp. 18-21, 2003.

[2] A. Spector, "Review: oxidative stress and disease," Journal of Ocular Pharmacology and Therapeutics, vol. 16, no. 2, pp. 193-201, 2000.

[3] L. Rittié and G. J. Fisher, "Natural and sun-induced aging of human skin," Cold Spring Harbor Perspectives in Medicine, vol. 5, no. 1, article a015370, 2015.

[4] N. Saewan and A. Jimtaisong, "Natural products as photoprotection," Journal of Cosmetic Dermatology, vol. 14, no. 1, pp. 47-63, 2015.

[5] L. Packer and K. Fuehr, "Low oxygen concentration extends the lifespan of cultured human diploid cells," Nature, vol. 267, no. 5610, pp. 423-425, 1977.

[6] T. von Zglinicki, G. Saretzki, W. Döcke, and C. Lotze, "Mild hyperoxia shortens telomeres and inhibits proliferation of fibroblasts: a model for senescence?," Experimental Cell Research, vol. 220, no. 1, pp. 186-193, 1995.
[7] Q. Chen and B. N. Ames, "Senescence-like growth arrest induced by hydrogen peroxide in human diploid fibroblast F65 cells," Proceedings of the National Academy of Sciences of the United States of America, vol. 91, no. 10, pp. 41304134, 1994.

[8] B. Chance, H. Sies, and A. Boveris, "Hydroperoxide metabolism in mammalian organs," Physiological Reviews, vol. 59, no. 3, pp. 527-605, 1979.

[9] J. M. Fukuto, S. J. Carrington, D. J. Tantillo et al., "Small molecule signaling agents: the integrated chemistry and biochemistry of nitrogen oxides, oxides of carbon, dioxygen, hydrogen sulfide, and their derived species," Chemical Research in Toxicology, vol. 25, no. 4, pp. 769-793, 2012.

[10] M. M. Cortese-Krott, A. Koning, G. G. C. Kuhnle et al., "The reactive species interactome: evolutionary emergence, biological significance, and opportunities for redox metabolomics and personalized medicine," Antioxidants \& Redox Signaling, vol. 27, no. 10, pp. 684-712, 2017.

[11] G. I. Giles and C. Jacob, "Reactive sulfur species: an emerging concept in oxidative stress," Biological Chemistry, vol. 383, no. 3-4, pp. 375-388, 2002.

[12] H.-U. Simon, A. Haj-Yehia, and F. Levi-Schaffer, "Role of reactive oxygen species (ROS) in apoptosis induction," Apoptosis, vol. 5, no. 5, pp. 415-418, 2000.

[13] N. Zamzami, P. Marchetti, M. Castedo et al., "Sequential reduction of mitochondrial transmembrane potential and generation of reactive oxygen species in early programmed cell death," Journal of Experimental Medicine, vol. 182, no. 2, pp. 367-377, 1995.

[14] V. Lobo, A. Patil, A. Phatak, and N. Chandra, "Free radicals, antioxidants and functional foods: impact on human health," Pharmacognosy Reviews, vol. 4, no. 8, pp. 118-126, 2010.

[15] D. de Beer, E. Joubert, W. C. A. Gelderblom, and M. Manley, "Phenolic compounds: a review of their possible role as in vivo antioxidants of wine," South African Journal of Enology \& Viticulture, vol. 23, no. 2, 2002.

[16] J.-L. Ravanat, C. Saint-Pierre, P. di Mascio, G. R. Martinez, M. H. G. Medeiros, and J. Cadet, "Damage to isolated DNA mediated by singlet oxygen," Helvetica Chimica Acta, vol. 84, no. 12, pp. 3702-3709, 2001.

[17] L. Claxton and G. Woodall JR., "A review of the mutagenicity and rodent carcinogenicity of ambient air," Mutation Research/Reviews in Mutation Research, vol. 636, no. 1-3, pp. 36-94, 2007.

[18] N. S. Dhalla, R. M. Temsah, and T. Netticadan, "Role of oxidative stress in cardiovascular diseases," Journal of Hypertension, vol. 18 , no. 6, pp. 655-673, 2000.

[19] I. Dalle-Donne, R. Rossi, R. Colombo, D. Giustarini, and A. Milzani, "Biomarkers of oxidative damage in human disease," Clinical Chemistry, vol. 52, no. 4, pp. 601-623, 2006.

[20] M. Valko, D. Leibfritz, J. Moncol, M. T. D. Cronin, M. Mazur, and J. Telser, "Free radicals and antioxidants in normal physiological functions and human disease," The International Journal of Biochemistry \& Cell Biology, vol. 39, no. 1, pp. 44-84, 2007.

[21] L. Sayre, M. Smith, and G. Perry, "Chemistry and biochemistry of oxidative stress in neurodegenerative disease," Current Medicinal Chemistry, vol. 8, no. 7, pp. 721-738, 2001.

[22] N. Gholamian-Dehkordi, T. Luther, M. Asadi-Samani, and M. R. Mahmoudian-Sani, "An overview on natural 
antioxidants for oxidative stress reduction in cancers; a systematic review," Immunopathologia Persa, vol. 3, no. 2, 2017.

[23] T. Sjoblom, S. Jones, L. D. Wood et al., "The consensus coding sequences of human breast and colorectal cancers," Science, vol. 314, no. 5797, pp. 268-274, 2006.

[24] C. M. Somers, B. McCarry, F. Malek, and J. S. Quinn, "Reduction of particulate air pollution lowers the risk of heritable mutations in mice," Science, vol. 304, no. 5673, pp. 10081010, 2004.

[25] H. E. Seifried, D. E. Anderson, E. I. Fisher, and J. A. Milner, "A review of the interaction among dietary antioxidants and reactive oxygen species," The Journal of Nutritional Biochemistry, vol. 18, no. 9, pp. 567-579, 2007.

[26] E. D. Lephart, "Skin aging and oxidative stress: Equol's antiaging effects via biochemical and molecular mechanisms," Ageing Research Reviews, vol. 31, pp. 36-54, 2016.

[27] O. Friedman, "Changes associated with the aging face," Facial Plastic Surgery Clinics of North America, vol. 13, no. 3, pp. 371-380, 2005.

[28] E. Lephart, "Equol's anti-aging effects protect against environmental assaults by increasing skin antioxidant defense and ECM proteins while decreasing oxidative stress and inflammation," Cosmetics, vol. 5, no. 1, p. 16, 2018.

[29] S. E. Mancebo and S. Q. Wang, "Recognizing the impact of ambient air pollution on skin health," Journal of the European Academy of Dermatology and Venereology, vol. 29, no. 12, pp. 2326-2332, 2015.

[30] K. E. Kim, D. Cho, and H. J. Park, "Air pollution and skin diseases: adverse effects of airborne particulate matter on various skin diseases," Life Sciences, vol. 152, pp. 126-134, 2016.

[31] H. Ushio, K. Nohara, and H. Fujimaki, "Effect of environmental pollutants on the production of pro-inflammatory cytokines by normal human dermal keratinocytes," Toxicology Letters, vol. 105, no. 1, pp. 17-24, 1999.

[32] P. Agostinis, M. Garmyn, and A. Van Laethem, "The aryl hydrocarbon receptor: an illuminating effector of the UVB response," Science's STKE, vol. 2007, no. 403, article pe49, 2007.

[33] Q. C. He, A. Tavakkol, K. Wietecha, R. Begum-Gafur, S. A. Ansari, and T. Polefka, "Effects of environmentally realistic levels of ozone on stratum corneum function," International Journal of Cosmetic Science, vol. 28, no. 5, pp. 349-357, 2006.

[34] J. Sowada, A. Schmalenberger, I. Ebner, A. Luch, and T. Tralau, "Degradation of benzo[a]pyrene by bacterial isolates from human skin," FEMS Microbiology Ecology, vol. 88, no. 1, pp. 129-139, 2014.

[35] C. Chen, X. Jiang, W. Zhao, and Z. Z. Zhang, "Dual role of resveratrol in modulation of genotoxicity induced by sodium arsenite via oxidative stress and apoptosis," Food and Chemical Toxicology, vol. 59, pp. 8-17, 2013.

[36] T. G. Rossman, "Mechanism of arsenic carcinogenesis: an integrated approach," Mutation Research/Fundamental and Molecular Mechanisms of Mutagenesis, vol. 533, no. 1-2, pp. 37-65, 2003.

[37] M. F. Hughes, B. D. Beck, Y. Chen, A. S. Lewis, and D. J. Thomas, "Arsenic exposure and toxicology: a historical perspective," Toxicological Sciences, vol. 123, no. 2, pp. 305332, 2011.

[38] R. Ruiz-Ramos, L. Lopez-Carrillo, A. D. Rios-Perez, A. De Vizcaya-Ruíz, and M. E. Cebrian, "Sodium arsenite induces
ROS generation, DNA oxidative damage, $\mathrm{HO}-1$ and c-Myc proteins, NF- $\kappa \mathrm{B}$ activation and cell proliferation in human breast cancer MCF-7 cells," Mutation Research/Genetic Toxicology and Environmental Mutagenesis, vol. 674, no. 12, pp. 109-115, 2009.

[39] Z. Zhang, X. Wang, S. Cheng et al., "Reactive oxygen species mediate arsenic induced cell transformation and tumorigenesis through Wnt/ $\beta$-catenin pathway in human colorectal adenocarcinoma DLD1 cells," Toxicology and Applied Pharmacology, vol. 256, no. 2, pp. 114-121, 2011.

[40] J. A. Imlay, "Pathways of oxidative damage," Annual Review of Microbiology, vol. 57, no. 1, pp. 395-418, 2003.

[41] T. K. Hei and M. Filipic, "Role of oxidative damage in the genotoxicity of arsenic," Free Radical Biology \& Medicine, vol. 37 , no. 5, pp. 574-581, 2004.

[42] T. S. Wang, C. F. Kuo, K. Y. Jan, and H. Huang, "Arsenite induces apoptosis in Chinese hamster ovary cells by generation of reactive oxygen species," Journal of Cellular Physiology, vol. 169, no. 2, pp. 256-268, 1996.

[43] D. F. Church and W. A. Pryor, "Free-radical chemistry of cigarette smoke and its toxicological implications," Environmental Health Perspectives, vol. 64, pp. 111-126, 1985.

[44] A. J. Sasco, M. B. Secretan, and K. Straif, "Tobacco smoking and cancer: a brief review of recent epidemiological evidence," Lung Cancer, vol. 45, pp. S3-S9, 2004.

[45] J. Wilbert, Tobacco and Shamanism in South America, Yale University Press, 1987.

[46] E. Schönherr, "Beitrag zur statistik und klinik der lungentumoren," Zeitschrift für Krebsforschung, vol. 27, no. 5, pp. 436-450, 1928.

[47] A. Morita, "Tobacco smoke causes premature skin aging," Journal of Dermatological Science, vol. 48, no. 3, pp. 169175, 2007.

[48] G. D. Smith and M. Egger, "The first reports on smoking and lung cancer: why are they consistently ignored?" Bulletin of the World Health Organization, vol. 83, pp. 799-800, 2005.

[49] P. Brennan and C. Fedor, "Sunlight, UV and accelerated weathering," Additives for Polymers, vol. 18, no. 7, p. 3, 1988.

[50] U. Panich, G. Sittithumcharee, N. Rathviboon, and S. Jirawatnotai, "Ultraviolet radiation-induced skin aging: the role of DNA damage and oxidative stress in epidermal stem cell damage mediated skin aging," Stem Cells International, vol. 2016, Article ID 7370642, 14 pages, 2016.

[51] H. Sies, C. Berndt, and D. P. Jones, "Oxidative stress," Annual Review of Biochemistry, vol. 86, no. 1, pp. 715-748, 2017.

[52] A. Ullrich and J. Schlessinger, "Signal transduction by receptors with tyrosine kinase activity," Cell, vol. 61, no. 2, pp. 203-212, 1990.

[53] S. Gross, A. Knebel, T. Tenev et al., "Inactivation of proteintyrosine phosphatases as mechanism of UV-induced signal transduction," Journal of Biological Chemistry, vol. 274, no. 37, pp. 26378-26386, 1999.

[54] G. J. Fisher, S. Kang, J. Varani et al., "Mechanisms of photoaging and chronological skin aging," Archives of Dermatology, vol. 138, no. 11, pp. 1462-1470, 2002.

[55] Y. Matsumura and H. N. Ananthaswamy, "Toxic effects of ultraviolet radiation on the skin," Toxicology and Applied Pharmacology, vol. 195, no. 3, pp. 298-308, 2004. 
[56] T. Komatsu, S. Sasaki, Y. Manabe, T. Hirata, and T. Sugawara, "Preventive effect of dietary astaxanthin on UVA-induced skin photoaging in hairless mice," PLoS One, vol. 12, no. 2, article e0171178, 2017.

[57] E. Shaulian and M. Karin, "AP-1 as a regulator of cell life and death," Nature Cell Biology, vol. 4, no. 5, pp. E131-E136, 2002.

[58] M. Schuler and D. R. Green, "Mechanisms of p53-dependent apoptosis," Biochemical Society Transactions, vol. 29, no. 6, pp. 684-688, 2001.

[59] L. Subedi, T. H. Lee, H. M. Wahedi, S.-H. Baek, and S. Y. Kim, "Resveratrol-enriched rice attenuates UVB-ROSinduced skin aging via downregulation of inflammatory cascades," Oxidative Medicine and Cellular Longevity, vol. 2017, Article ID 8379539, 15 pages, 2017.

[60] J. Chen, Y. Li, Q. Zhu et al., "Anti-skin-aging effect of epigallocatechin gallate by regulating epidermal growth factor receptor pathway on aging mouse model induced by d -galactose," Mechanisms of Ageing and Development, vol. 164, pp. 1-7, 2017.

[61] A. I. Khlebnikov, I. A. Schepetkin, N. G. Domina, L. N. Kirpotina, and M. T. Quinn, "Improved quantitative structure-activity relationship models to predict antioxidant activity of flavonoids in chemical, enzymatic, and cellular systems," Bioorganic \& Medicinal Chemistry, vol. 15, no. 4, pp. 1749-1770, 2007.

[62] B. Halliwell, "Antioxidants: the basics-what they are and how to evaluate them," Advances in Pharmacology, vol. 38, pp. 3-20, 1996.

[63] L. L. Ji, Y. C. Sheng, Z. Y. Zheng, L. Shi, and Z. T. Wang, "The involvement of p62-Keap1-Nrf2 antioxidative signaling pathway and JNK in the protection of natural flavonoid quercetin against hepatotoxicity," Free Radical Biology \& Medicine, vol. 85, pp. 12-23, 2015.

[64] R. Kanlaya, S. Khamchun, C. Kapincharanon, and V. Thongboonkerd, "Protective effect of epigallocatechin3-gallate (EGCG) via Nrf2 pathway against oxalateinduced epithelial mesenchymal transition (EMT) of renal tubular cells," Scientific Reports, vol. 6, no. 1, article 30233, 2016.

[65] M. Valko, C. J. Rhodes, J. Moncol, M. Izakovic, and M. Mazur, "Free radicals, metals and antioxidants in oxidative stress-induced cancer," Chemico-Biological Interactions, vol. 160 , no. 1, pp. 1-40, 2006.

[66] N. I. Krinsky, "Mechanism of action of biological antioxidants," Experimental Biology and Medicine, vol. 200, no. 2, pp. 248-254, 1992.

[67] E. F. Bernstein, S. K. Kong, D. B. Brown et al., "The nitroxide Tempol affords protection against ultraviolet radiation in a transgenic murine fibroblast culture model of cutaneous photoaging," Experimental Dermatology, vol. 10, no. 1, pp. 55-61, 2001.

[68] E. Venditti, F. Brugè, P. Astolfi, I. Kochevar, and E. Damiani, "Nitroxides and a nitroxide-based UV filter have the potential to photoprotect UVA-irradiated human skin fibroblasts against oxidative damage," Journal of Dermatological Science, vol. 63 , no. 1, pp. 55-61, 2011.

[69] E. Bernstein, "Use of nitroxides in wound healing and in the prevention of photodamage," US Patent 6,552,040, 2003.

[70] S. Yan, X. Hong, Y. Hu, and K. Liao, "Tempol, one of nitroxides, is a novel ultraviolet-A1 radiation protector for human dermal fibroblasts," Journal of Dermatological Science, vol. 37, no. 3, pp. 137-143, 2005.

[71] D. H. McDaniel, B. A. Neudecker, J. DiNardo, J. A. Lewis, and H. I. Maibach, "Clinical efficacy assessment in photodamaged skin of $0.5 \%$ and $1.0 \%$ idebenone," Journal of Cosmetic Dermatology, vol. 4, no. 3, pp. 167-173, 2005.

[72] D. Singh Joshan and S. K. Singh, "Investigational study of Juglans regia extract and quercetin against photoaging," Biomedicine \& Aging Pathology, vol. 3, no. 4, pp. 193-200, 2013.

[73] F. T. M. C. Vicentini, T. He, Y. Shao et al., "Quercetin inhibits UV irradiation-induced inflammatory cytokine production in primary human keratinocytes by suppressing NF- $\kappa \mathrm{B}$ pathway," Journal of Dermatological Science, vol. 61, no. 3, pp. 162-168, 2011.

[74] G. Petruk, A. Illiano, R. Del Giudice et al., "Malvidin and cyanidin derivatives from açai fruit (Euterpe oleracea Mart.) counteract UV-A-induced oxidative stress in immortalized fibroblasts," Journal of Photochemistry and Photobiology B: Biology, vol. 172, pp. 42-51, 2017.

[75] K. Park and J. H. Lee, "Protective effects of resveratrol on UVB-irradiated $\mathrm{HaCaT}$ cells through attenuation of the caspase pathway," Oncology Reports, vol. 19, no. 2, pp. 413417, 2008.

[76] F. Afaq, V. M. Adhami, and N. Ahmad, "Prevention of shortterm ultraviolet $\mathrm{B}$ radiation-mediated damages by resveratrol in SKH-1 hairless mice," Toxicology and Applied Pharmacology, vol. 186, no. 1, pp. 28-37, 2003.

[77] D. Buonocore, Nobile, Cestone et al., "Resveratrol-procyanidin blend: nutraceutical and antiaging efficacy evaluated in a placebo-controlled, double-blind study," Clinical, Cosmetic and Investigational Dermatology, vol. 5, pp. 159-165, 2012.

[78] S. Cho, D. H. Lee, C. H. Won et al., "Differential effects of low-dose and high-dose beta-carotene supplementation on the signs of photoaging and type I procollagen gene expression in human skin in vivo," Dermatology, vol. 221 , no. 2 , pp. 160-171, 2010.

[79] S. Grether-Beck, A. Marini, T. Jaenicke, W. Stahl, and J. Krutmann, "Molecular evidence that oral supplementation with lycopene or lutein protects human skin against ultraviolet radiation: results from a double-blinded, placebo-controlled, crossover study," British Journal of Dermatology, vol. 176, no. 5, pp. 1231-1240, 2017.

[80] R. Del Giudice, G. Petruk, A. Raiola, A. Barone, D. M. Monti, and M. M. Rigano, "Carotenoids in fresh and processed tomato (Solanum lycopersicum) fruits protect cells from oxidative stress injury," Journal of the Science of Food and Agriculture, vol. 97, no. 5, pp. 1616-1623, 2017.

[81] P. K. Farris, “Topical vitamin C: a useful agent for treating photoaging and other dermatologic conditions," Dermatologic Surgery, vol. 31, Supplement 1, pp. 814-818, 2005.

[82] F. Al-Niaimi and N. Y. Z. Chiang, "Topical vitamin C and the skin: mechanisms of action and clinical applications," The Journal of Clinical and Aesthetic Dermatology, vol. 10, no. 7, pp. 14-17, 2017.

[83] G. Petruk, A. Raiola, R. Del Giudice et al., "An ascorbic acidenriched tomato genotype to fight UVA-induced oxidative stress in normal human keratinocytes," Journal of Photochemistry and Photobiology B: Biology, vol. 163, pp. 284289, 2016. 
[84] E. A. Offord, J.-C. Gautier, O. Avanti et al., "Photoprotective potential of lycopene, $\beta$-carotene, vitamin $\mathrm{E}$, vitamin $\mathrm{C}$ and carnosic acid in UVA-irradiated human skin fibroblasts," Free Radical Biology \& Medicine, vol. 32, no. 12, pp. 12931303, 2002.

[85] B. A. Jurkiewicz, D. L. Bissett, and G. R. Buettner, "Effect of topically applied tocopherol on ultraviolet radiation- mediated free radical damage in skin," Journal of Investigative Dermatology, vol. 104, no. 4, pp. 484-488, 1995.

[86] A. Godic, B. Poljšak, M. Adamic, and R. Dahmane, "The role of antioxidants in skin cancer prevention and treatment," Oxidative Medicine and Cellular Longevity, vol. 2014, Article ID 860479, 6 pages, 2014.

[87] C.-S. Cătană, A. G. Atanasov, and I. Berindan-Neagoe, "Natural products with anti-aging potential: affected targets and molecular mechanisms," Biotechnology Advances, 2018.

[88] M. Cavinato, B. Waltenberger, G. Baraldo, C. V. C. Grade, H. Stuppner, and P. Jansen-Dürr, "Plant extracts and natural compounds used against UVB-induced photoaging," Biogerontology, vol. 18, no. 4, pp. 499-516, 2017.

[89] V. Kostyuk, A. Potapovich, A. R. Albuhaydar, W. Mayer, C. De Luca, and L. Korkina, "Natural substances for prevention of skin photoaging: screening systems in the development of sunscreen and rejuvenation cosmetics," Rejuvenation Research, vol. 21, no. 2, pp. 91-101, 2018.

[90] R. Bosch, N. Philips, J. Suárez-Pérez et al., "Mechanisms of photoaging and cutaneous photocarcinogenesis, and photoprotective strategies with phytochemicals," Antioxidants, vol. 4, no. 2, pp. 248-268, 2015.

[91] G. Petruk, F. Di Lorenzo, P. Imbimbo et al., "Protective effect of Opuntia ficus-indica L. cladodes against UVA-induced oxidative stress in normal human keratinocytes," Bioorganic \& Medicinal Chemistry Letters, vol. 27, no. 24, pp. 54855489, 2017.

[92] C. Smith, "Natural antioxidants in prevention of accelerated ageing: a departure from conventional paradigms required," Journal of Physiology and Biochemistry, 2018.

[93] D. N. Che, G. H. Xie, B. O. Cho, J. Y. Shin, H. J. Kang, and S. I. Jang, "Protective effects of grape stem extract against UVB-induced damage in C57BL mice skin," Journal of Photochemistry and Photobiology B: Biology, vol. 173, pp. 551-559, 2017.

[94] S. Davinelli, J. C. Bertoglio, A. Polimeni, and G. Scapagnini, "Cytoprotective polyphenols against chronological skin aging and cutaneous photodamage," Current Pharmaceutical Design, vol. 24, no. 2, pp. 99-105, 2018.

[95] H. H. Chow, I. A. Hakim, D. R. Vining et al., "Effects of dosing condition on the oral bioavailability of green tea catechins after single-dose administration of polyphenon $\mathrm{E}$ in healthy individuals," Clinical Cancer Research, vol. 11, no. 12, pp. 4627-4633, 2005.

[96] H.-S. Kim, M. J. Quon, and J.-a. Kim, "New insights into the mechanisms of polyphenols beyond antioxidant properties; lessons from the green tea polyphenol, epigallocatechin 3-gallate," Redox Biology, vol. 2, pp. 187-195, 2014.

[97] U. Heinrich, K. Neukam, H. Tronnier, H. Sies, and W. Stahl, "Long-term ingestion of high flavanol cocoa provides photoprotection against UV-induced erythema and improves skin condition in women," The Journal of Nutrition, vol. 136, no. 6, pp. 1565-1569, 2006.
[98] M. Levine, S. C. Rumsey, R. Daruwala, J. B. Park, and Y. Wang, "Criteria and recommendations for vitamin C intake," JAMA, vol. 281, no. 15, pp. 1415-1423, 1999.

[99] A. Costa, E. Pereira, E. Assumpcao et al., "Assessment of clinical effects and safety of an oral supplement based on marine protein, vitamin $\mathrm{C}$, grape seed extract, zinc, and tomato extract in the improvement of visible signs of skin aging in men," Clinical, Cosmetic and Investigational Dermatology, vol. 8, pp. 319-328, 2015.

[100] J. Pullar, A. Carr, and M. Vissers, "The roles of vitamin C in skin health," Nutrients, vol. 9, no. 8, p. 866, 2017.

[101] S. Grether-Beck, A. Marini, T. Jaenicke, and J. Krutmann, "Effective photoprotection of human skin against infrared a radiation by topically applied antioxidants: results from a vehicle controlled, double-blind, randomized study," Photochemistry and Photobiology, vol. 91, no. 1, pp. 248-250, 2015.

[102] N. P. J. Stamford, "Stability, transdermal penetration, and cutaneous effects of ascorbic acid and its derivatives," Journal of Cosmetic Dermatology, vol. 11, no. 4, pp. 310-317, 2012.

[103] J. M. Sagawa, L. E. Stanley, A. M. LaFountain, H. A. Frank, C. Liu, and Y.-W. Yuan, "An R2R3-MYB transcription factor regulates carotenoid pigmentation in Mimulus lewisii flowers," The New Phytologist, vol. 209, no. 3, pp. 10491057, 2016.

[104] W. Stahl, U. Heinrich, S. Wiseman, O. Eichler, H. Sies, and H. Tronnier, "Dietary tomato paste protects against ultraviolet light-induced erythema in humans," The Journal of Nutrition, vol. 131, no. 5, pp. 1449-1451, 2001.

[105] U. Heinrich, C. Gärtner, M. Wiebusch et al., "Supplementation with $\beta$-carotene or a similar amount of mixed carotenoids protects humans from UV-induced erythema," The Journal of Nutrition, vol. 133, no. 1, pp. 98-101, 2003.

[106] H. Sies and W. Stahl, "Carotenoids and UV protection," Photochemical \& Photobiological Sciences, vol. 3, no. 8, pp. 749752, 2004.

[107] W. Stahl and H. Sies, "Photoprotection by dietary carotenoids: concept, mechanisms, evidence and future development," Molecular Nutrition \& Food Research, vol. 56, no. 2, pp. 287-295, 2012.

[108] E. Fernández-García, I. Carvajal-Lérida, and A. Pérez-Gálvez, "Carotenoids exclusively synthesized in red pepper (capsanthin and capsorubin) protect human dermal fibroblasts against UVB induced DNA damage," Photochemical \& Photobiological Sciences, vol. 15, no. 9, pp. 1204-1211, 2016.

[109] C. H. Hennekens, J. E. Buring, J. E. Manson et al., "Lack of effect of long-term supplementation with beta carotene on the incidence of malignant neoplasms and cardiovascular disease," The New England Journal of Medicine, vol. 334, no. 18, pp. 1145-1149, 1996.

[110] A. Ascenso, T. Pedrosa, S. Pinho et al., "The effect of lycopene preexposure on UV-B-irradiated human keratinocytes," Oxidative Medicine and Cellular Longevity, vol. 2016, Article ID 8214631, 15 pages, 2016.

[111] O. Aust, W. Stahl, H. Sies, H. Tronnier, and U. Heinrich, "Supplementation with tomato-based products increases lycopene, phytofluene, and phytoene levels in human serum and protects against UV-light-induced erythema," 
International Journal for Vitamin and Nutrition Research, vol. 75, no. 1, pp. 54-60, 2005.

[112] M. Rizwan, I. Rodriguez-Blanco, A. Harbottle, M. A. BirchMachin, R. E. B. Watson, and L. E. Rhodes, "Tomato paste rich in lycopene protects against cutaneous photodamage in humans in vivo: a randomized controlled trial," British Journal of Dermatology, vol. 164, no. 1, pp. 154-162, 2011.

[113] J. L. Cooperstone, K. L. Tober, K. M. Riedl et al., “Tomatoes protect against development of UV-induced keratinocyte carcinoma via metabolomic alterations," Scientific Reports, vol. 7, no. 1, p. 5106, 2017. 


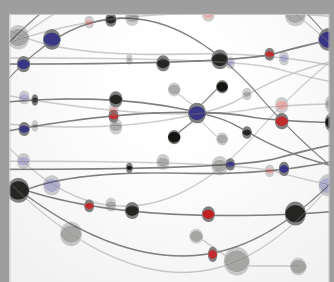

The Scientific World Journal
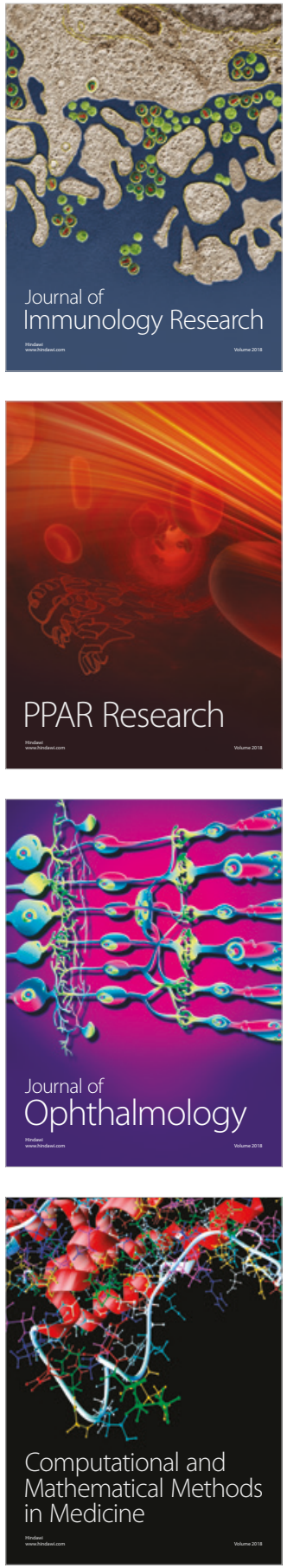

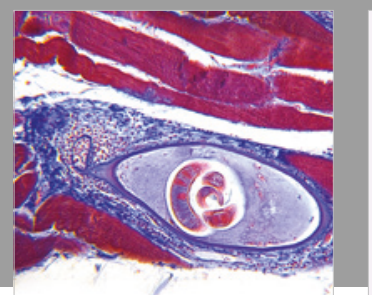

Gastroenterology Research and Practice

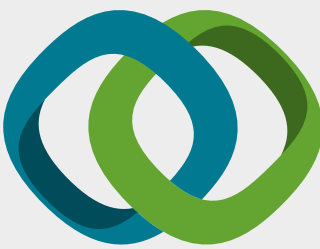

\section{Hindawi}

Submit your manuscripts at

www.hindawi.com
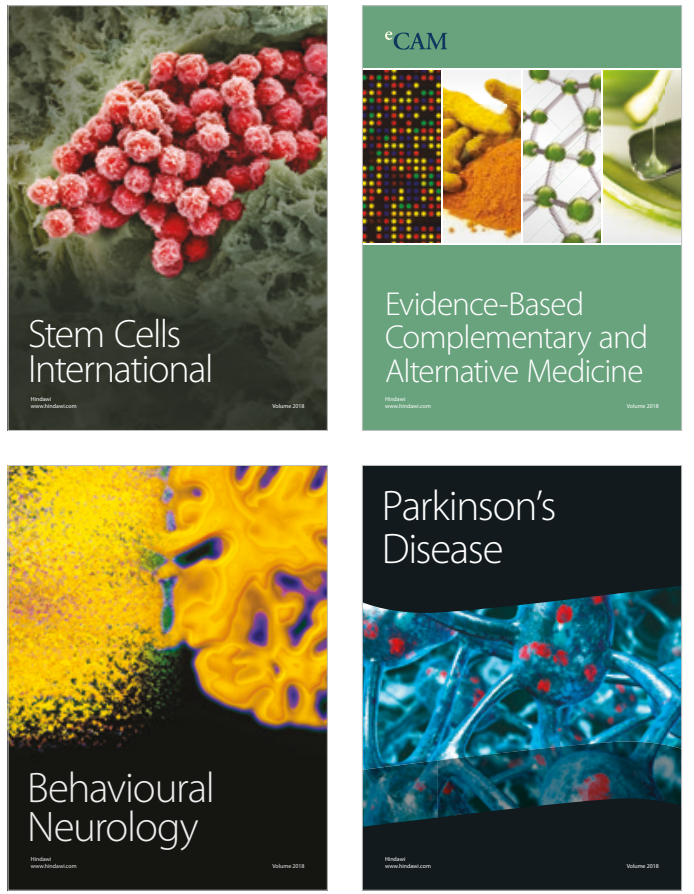

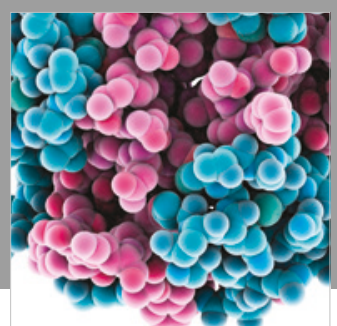

ournal of

Diabetes Research

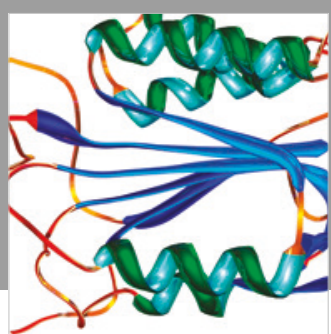

Disease Markers
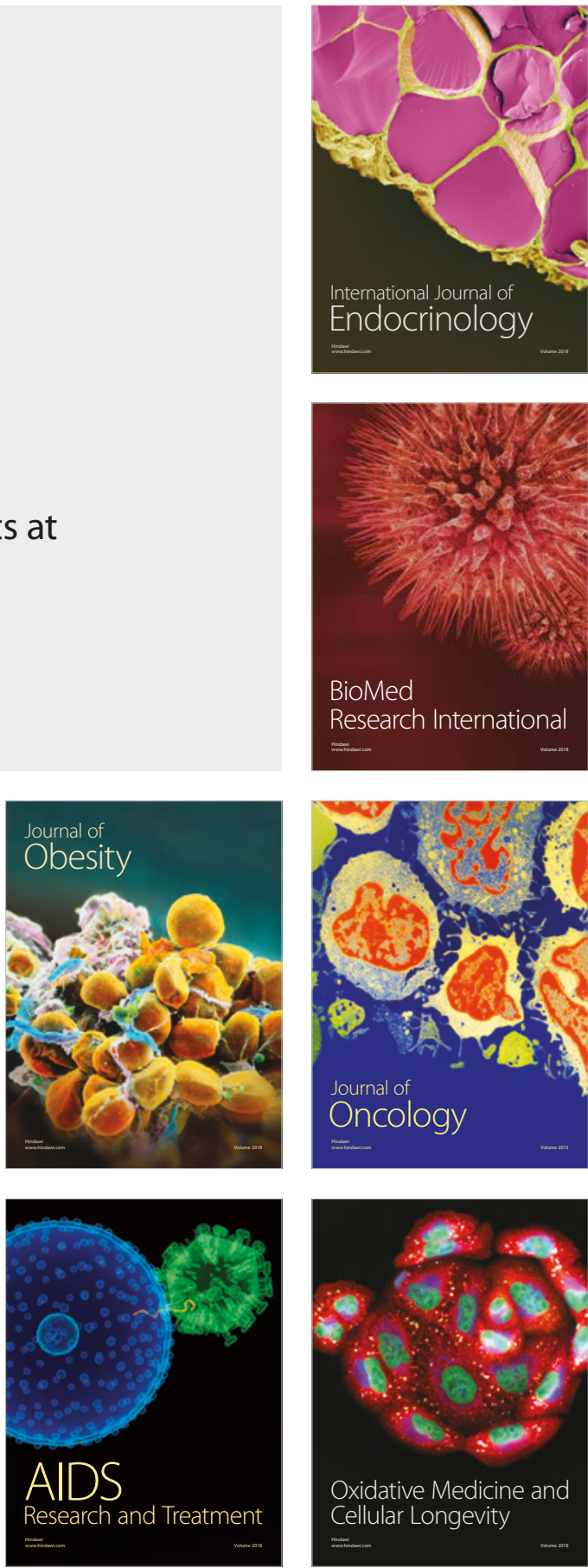